\title{
The Opinions of the Teachers on Mentoring Process and Experiences
}

\author{
Morakane C. Mphojane, Awelani M. Rambuda* \\ Department of Educational and Professional Studies, Faculty of Humanities, Central University of Technology, Free State, South \\ Africa
}

Received May 26, 2021; Revised July 6, 2021; Accepted August 22, 2021

\begin{abstract}
Cite This Paper in the following Citation Styles
(a): [1] Morakane C. Mphojane, Awelani M. Rambuda, "The Opinions of the Teachers on Mentoring Process and Experiences," Universal Journal of Educational Research, Vol. 9, No. 12, pp. 1935 - 1948, 2021. DOI: 10.13189/ujer.2021.091206.
\end{abstract}

(b): Morakane C. Mphojane, Awelani M. Rambuda (2021). The Opinions of the Teachers on Mentoring Process and Experiences. Universal Journal of Educational Research, 9(12), 1935 - 1948. DOI: 10.13189/ujer.2021.091206.

Copyright $(2021$ by authors, all rights reserved. Authors agree that this article remains permanently open access under the terms of the Creative Commons Attribution License 4.0 International License

\begin{abstract}
The aim of this phenomenological qualitative study was to explore the opinions of the teachers on mentoring process and their experiences. To achieve this aim, the study sought information on mentoring essences, practices, roles, and training needs of mentor teachers. Experienced and beginning teachers were purposefully selected from eight English-medium secondary schools in South Africa. Data from the literature review, 16 group interviews and 24 open-ended questionnaires were triangulated and thematically analysed to gain a deeper understanding of the phenomenon. Forty-eight experienced teachers and 24 beginning teachers shared their life experiences, perspectives, and perceptions on the mentoring process. The study revealed that in South African schools, mentoring was patchy and unsystematic. Data collected revealed that a new working environment presented some social, personal, and professional challenges to beginning teachers. It was revealed that experienced teachers were willing to support their fellow beginning colleagues even though they were not trained in the mentoring process and did not receive the necessary support from the school management teams.
\end{abstract}

Keywords Beginning Teachers, Essences of Mentoring, Formal Mentoring, Mentoring, Mentoring Experiences, Mentoring Model, Mentoring Practices, Mentoring Process, Mentoring Programme, Mentoring Relations, Experienced Teachers

\section{Introduction}

The transition of beginning teachers from universities to their real-life jobs is somewhat daunting. In most cases, the theory they obtained during their training is contrary to real-life experiences at schools. At this stage, beginning teachers are usually met with the emotional and ecological challenges of becoming accustomed to the new work environment and new colleagues. To counter this daunting new experience, experienced teachers could be of assistance in assuring beginning teachers that their lack of experience was normal. They could sympathise with beginning teachers, offer them support and advice to make them feel welcomed, thereby reducing their stress levels [1]. A beginning teacher's assistance must be treated as a package that entails support to their whole being, such as personal, emotional, and professional aspects. These should include problem-solving skills that enable them to look at the teaching profession and their contributions in a critical manner [1]. Experienced teachers who usually serve as mentors, though not officially assigned, are essential supporters in directing beginning teachers to improve their subject expertise and methodology.

\section{Research Aim, Question and Objective}

The aim of this research is to explore the opinions of the teachers on mentoring process and their experiences. 
This aim leads to the following research question:

- Is the mentoring process of beginning teachers effective at schools in South Africa?

The objective of this study is to develop a model for formal mentoring of beginning teachers.

\section{Background to the Study}

In their Consortium for Policy Research in Education (CPRE) report, Ingersoll et al. [2] document an increase in the intake of the teaching force. According to this report, most of these new appointees are youth who just graduated from universities. As much as new teachers can be a source of fresh ideas and energy, it is also important to have experienced teachers who can nurture these beginning teachers into their new responsibilities. Research into the mentoring process of pre-service teachers regards mentoring as one of the main factors that contribute to the beginning teacher's success in their teaching career [3]. Ingersoll and Strong [4] assert that guidance and support offered by experienced teachers to their fellow beginning colleagues yield positive results in that their teaching skills, learner performance and retention are all improved. Support given to beginning teachers is spontaneous and haphazard, without forming part of the school's formal programme that can be enforced [5]. Formal mentoring that is systemic and which forms part of the organisation's development plans is needed. Where formal mentoring is done, people are usually paired according to their compatibility [6]. Kahle-Piasecki [7] affirms that where formal mentoring takes place, through formal processes, mentees are allocated to mentor teachers in accordance with the specific needs of mentees. However, there is no formal or structured mentoring model offered at the schools in South Africa.

\subsection{Formal Mentoring}

The definition of mentoring is very broad in teaching profession. Fragoulis [8] argues that mentoring is inspired by the character of a mentor in Homer's Odyssey. Mentor was the elderly friend who served as a counsellor to Odysseus's son Telemachus. According to McLaughlin [9], a mentor is now regarded in a short and simple term as "a wise and trusted teacher or counsellor" (p. 872). Kahle-Piasecki [7] asserts that mentoring could be defined from the verb 'mentor' which means educating and providing knowledge for a beginning teacher. There is a close connection between an experienced and a less experienced person; it gives knowledge, guidance, and support through conduct by the experienced person [10]. Mentoring magnifies one's perception of oneself and improves the beginning teacher's professional growth.
Mentoring can take place either formally or informally. In informal mentoring, there is no official process, no compensation, training or time-release for those involved [11]. Nevertheless, with well-structured mentoring, the experienced teachers are knowledgeable about providing the required aid, which most inexperienced teachers do not necessarily get [12].

In a casual and unorganised mentoring procedure, the less experienced person (the mentee) requires the more experienced one (the mentor) to provide information about a career or be their guide. Informal mentoring also happens when an adequately knowledgeable person (mentor) voluntarily provides services for a person (mentee) they know. The person can gain a great deal from the information provided [13]. This interconnectedness strengthens over time and has the power to produce the required effect. The people involved in informal mentoring relationships may be from different organisations [13]. Hoffer [14] describes informal mentoring as a connection that develops naturally between two people where one requires personal and career development and looks upon someone for consistent guidance and motivation. Vikaraman et al. [15] affirm that casual relationships unfold spontaneously between the experienced teacher and the beginning teachers who go through the system, besides learning and advancing their inquiry knowledge. A mentor should be well informed and ready to provide the required help. It is imperative to establish an atmosphere conducive or the casual interactions between the mentor and the mentee to thrive.

Furthermore, a well-structured and organised mentoring relationship relates to mentoring that is planned and is part of the official programme, where both the mentor and the mentee are from the same organisation. The relationship which exists has been the idea and the formation of organisational hierarchy [16]. Planned and formal mentoring usually demands training. The organisation establishes who requires assistance and who should be appraised and rewarded. The time for formal mentoring is strictly adhered to without fail [13]. Kahle-Piasecki [7] affirms that this kind of mentoring occurs through a structured programme in which mentors and mentees are carefully selected and matched through a formal process. Mentors receive training and mentoring programmes are developed in line with the goals of the organisation. Formal mentoring is a structured approach in the mentoring process as opposed to informal mentoring, where relationships develop naturally. In a formal mentoring programme, individuals do not get to choose their mentoring partners, while the organisation does. However, it is cautioned that designated mentoring interaction may not yield desired results as the one that develops spontaneously, because of personal clashes and the absence of sincerity because the mentor-mentee relationship is not established by their own proposal [17]. Additionally, Tummons et al. [18] argue that 
well-structured and organised mentoring schedules may limit the formation of high-quality mentoring connections between mentor and mentee. The two participants are often marked with feelings of awkwardness, anxiety, tentativeness, and feelings of scepticism. However, Beane-Katner [19] asserts that formal mentoring is the way to go. The traditional or the informal ways of mentoring a new faculty member should be done away with. This is because it does not perfectly match the characteristics of the next-generation faculty, as it is hard to find a chance to create mentoring in casual settings. Fragoulis [8] indicates that formal mentoring has some benefits, namely:

- it offers help and guidance from an experienced person to a person with less experience in the frame of an interpersonal relationship, which is developed between the two people;

- gives to the protégé the broader picture of the socio-economic and educational frame in which the educational programme is implemented;

- offers the protégé learning opportunities in a non-threatening environment;

- supports the inexperienced teacher in matters of design, organisation, implementation, and evaluation of innovative educational programmes;

- offers help in resolving problems which arise during the implementation of innovative educational programmes (p.52).

These benefits imply that if properly planned and fully implemented, formal mentoring programmes offer both emotional and instructional support to the mentee [20]. Though the focus might be on the progress of effective classroom management, broadening the subject knowledge and teaching methods, mentees themselves should be allowed to inform the programme by being given the opportunity to indicate their areas of development. Effective formal mentoring programmes do not only add to the improvement of status and expected standards of beginning teachers, but also assist and enhance the expertise of teachers in the whole school [21].

\section{Competence Levels after Informal and Formal Mentoring}
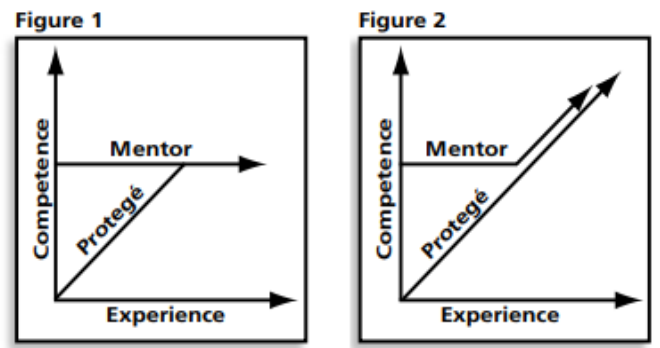

Figure 1. Competence levels after informal and formal mentoring [22, p.9].

Figure 1 depicts competence levels which exist after informal and formal mentoring. The first image (left) represents teacher growth in an informal "buddy" mentoring relationship, where the mentor gains experience in mentoring but does not grow professionally. The second image (right) shows professional growth in both the beginning teacher and the mentor when the mentoring offered is supported within a formalised programme.

\subsection{Mentoring Programme}

A formal mentoring programme is a well-thought plan which outlines how mentoring should be done in line with the set organisation objectives. The programme is an official activity that must be supported by everyone in the organisation. The organisation sets up a structure and draws some guidelines that dictate how mentoring relationships are to unfold from the beginning until the end and how they are to be maintained and improved [23]. Formal organisational mentoring programmes often seek to address specific development needs or an organisational issue, such as an employee retention strategy. Usually, specific short-term and long-term objectives are set for a formal programme and all necessary human and capital resources are offered to help realise or accomplish the set objectives [24]. A formal mentoring programme offers support to participants. Ongoing monitoring of the programme ensures that the expected outcomes are achieved. Mentoring programmes are designed to provide guidance and direction above and beyond that offered through the employee's management chain [24]. In this study, a mentoring programme is regarded as a model or framework which is used by schools as a guide on how beginning teachers are to be supported in order to function optimally.

An effective formal mentoring schedule rewards inexperienced teachers' insufficient preparation and lowers the level of resignations [25]. Dishena and Mokoena [26] contend that people crave connection and therefore mentoring programmes which promote interaction are necessary and provide job satisfaction. Additionally, giving sufficient guidance and assistance to beginning teachers ensures that capable, skillful, knowledgeable, and highly qualified teachers are kept in the profession [25]. Through mentoring processes, new teachers can mix, thereby promoting good human relations at schools.

Wechsler et al. [27] assert that well-planned effective formal mentoring plans enable new teachers to celebrate their colleagues, to be celebrated themselves and be part of interconnected systems that motivate them to perform at the utmost level of their abilities. Kutsyuruba et al. [28] report that well-thought teacher-mentoring programmes are linked with high teacher morale and career commitment. Ambrosetti [29] indicates that mentors see mentoring as the opportunity to make a positive difference 
for other professionals. Ambrosetti [29] further argues that mentors perceive mentoring as an opportunity to look back on their strategies and energise them. Ingersoll [30] claims that the inexperienced teachers who have been inducted excel in different fields of teaching, for example, ensuring that learners concentrate on the activity given, drawing appropriate plans that fit the current situation, employing relevant questioning methods, changing the classroom tasks, and making them appeal to learners' attention and curiosity, keeping the exuberant mood in the classroom and showing their best in maintaining their classes. This shows that teachers who are actively involved in professional development programmes, particularly mentoring become empowered and are most possibly going to stay in the teaching profession for a long time to come. Mentoring and professional advancement chances are the main factors that teachers consider for staying in the profession [31]. It can be concluded, therefore, that promoting professional integration through informal or formal mentoring and other professional programme is essential for teacher capacitation, retention, and job satisfaction [26]. Contrary to these findings, however, some researchers argue that mentoring has virtually no impact on retaining employees [32].

Drawing from one of the researchers' past experiences as a former teacher and principal, the researchers concur that mentoring is critical in nurturing beginning teachers. However, it is considered that mentoring alone is not sufficient to keep teachers in the profession as many teachers who are dedicated and motivated to work do find themselves tempted to go for other jobs due to salary packages and better working conditions. Though mentoring is deemed necessary, its nature whether formal or informal has a bearing on the expected results.

\subsection{The Role of Experienced Teachers in the Mentoring Process}

The presence of experienced teachers is necessary for building the teaching capacities of beginning teachers. The success of mentoring is reliant on the skills and knowledge of the mentors who enact the mentorship role, rather than on mere experience, which accumulates with age [33]. It can, therefore, be assumed that not everybody can become an effective mentor since mentors might not have experienced struggles like the ones experienced by beginning teachers and that not all experienced teachers have the necessary skills and knowledge necessary to handle beginning teachers' problems. Mentors should be well-selected, well-trained, and given the time to work intensively with their mentees. Mentors should not only help beginning teachers to become good but should also help create a healthy atmosphere which promotes effective teaching and learning.

Mentors must provide guidance in a productive manner. They must be able to identify and develop the potential of their mentees and emphasise the importance of ongoing communication. Cho et al. [34] suggest a continuous and healthy conversation between the mentor and mentee to ensure that the set goals are achieved. Good mentors should aim at leading the mentees to success in their profession. Furthermore, Cho et al. [34] claim that a mentor should have admirable personal qualities. An effective mentor must be energetic, compassionate, generous, honest, insightful, and selfless and have good time management skills. It is further argued that an excellent mentor is a person who assists the mentees to find solutions by themselves rather than providing them with ready-made answers [35]. Experienced teachers tend to accept that their main responsibility is to give instructional and sentimental assistance, aid with paperwork and planning and give information about processes and governance and provide answers to problems as true [36]. Iancu-Haddad and Oplatka [37] affirm that good mentors do understand and are willing to execute their responsibilities of helping beginning teachers by being empathetic on all levels and acquainting the beginning teachers with the norms and values of the institution.

\section{Personal Support}

Personal support rendered by mentors to beginning teachers in trying to help them cope with the transitional challenges they encounter during their first years of teaching is necessary and does help. The transitional challenges beginning teachers experience can sometimes lead to despair, heightened levels of stress, uneasiness and make teachers wonder if they really are competent in their work [38]. Mentoring programmes assist beginning teachers and enable them to create their own identity as teachers [39]. Ingersoll and Strong [4] submit that teachers who once participated in mentoring schedules recount high levels of capability, motivation, alertness and support due to having gone through the mentoring process. Mentoring does not only provide emotional support, but also builds up healthy relations among staff members. The level of emotional support they receive plays a significant role in determining the existence and continuance of the relationship with their mentors as well as their stay in the profession. Ingersoll [30] affirms that teachers who had access to mentors in their inception to teaching were unlikely to leave the field. Early experiences have significant influences on teachers' practices and attitudes to their profession, including how they are being socialised into their new environment and into the profession.

\section{Social Support}

Mentoring programmes create a common time for new teachers to formally meet and work together with their experienced colleagues. These partnerships stimulate feedback and the exchange of new ideas. Beginning 
teachers can sense being part of the team that accepts new perspectives [5]. Aspfors [40] also affirms that social support enables the creation and support of a collaborative learning environment within the school and between the stakeholders in the educational system (district officials, parents, community, etc.). Another important factor in the social support of beginning teachers in schools is the school culture. Through their social interactions with their experienced colleagues, beginning teachers get to learn about the tradition and culture of the school.

Correct matching of mentees to mentors for professional support is important. Mentors can help mentees with the development of good classroom practice(s) and can even provide constructive feedback that supports professional reflective dialogue [41]. The way a beginning teacher is ushered at the school and into a new job has a bearing on the productivity and life span of the teacher in the profession. In most schools, teachers spend much of their school day in the classrooms, isolated from contact with their fellow colleagues. Nantanga [42] confirms that beginning teachers may face problems of being neglected and not being part of the whole, as there are already groups in the school with very close ties. On the contrary, Iancu-Haddad and Oplatka [37] assert that beginning teachers may positively or negatively influence the prestige of the school and based on their reputation, talents and content knowledge, professional envy and disagreements may surface among experienced and beginning teachers.

\section{Professional Support}

Professional support through mentoring programmes is the start of an endless journey of post-initial learning and it is intended to close the gap between earlier teacher training and the actual teaching environment [43]. Deacon [44] professes that professional support empowers beginning teachers and other staff members. Vikaraman et al. [15] advocate that professional support creates a healthy, professional working environment. Mentoring programmes help beginning teachers sense that they are aided and cherished by other professionals [20]. Deacon [44] maintains that quality mentoring requires mentors to acquire knowledge as to exactly when they should give assistance to mentees and when they should distance themselves to allow mentees to be able to walk the path on their own. Mentees differ with respect to their personalities, skills and expertise; thus, mentors are expected to be knowledgeable about what mentoring knowledge, skills, and expertise they should use to be able to offer appropriate personal and professional development to the mentees. Mentors need to be attentive to the particularities and diversities of the mentoring context and become aware that not everything is for everybody. Iancu-Haddad and Oplatka [37] suggest that all teacher mentors should have access to a model of mentoring knowledge before they could assume their duty as mentors. This would ensure that there is consistency in 'good' practice across all schools within the country and will also contribute to better quality mentoring programmes being instituted at the different schools. According to European Commission Staff Working Document SEC [5], elements of professional support could be:

- Contributions by experts (e.g., from universities). This can be organised through formal courses or information sessions or by the opportunity to consult experts.

- Exchange of practical knowledge between beginning and experienced teachers (in different schools), for example through participation in collaborative learning communities (p. 18).

Mentoring is a good strategy for professional development, and it should be well-planned, understood by those involved and be properly carried out.

\section{Research Design and Methodology}

This study follows a qualitative approach, using a phenomenological design. In a phenomenological study, the researcher seeks to understand the essences of the phenomenon by looking into the participants' experiences, perceptions, and perspectives [45]. Leedy and Ormrod [46] confirm that in a phenomenological study, the researcher describes and interprets the participants' perceptions, perspectives, and understandings of a particular situation. A phenomenological design was used to explore the teachers' experiences and opinions on the mentoring of beginning teachers at schools. A research design is a logical set of procedures that outline how the researcher is to collect, analyse and report their data in a research study [47]. The researchers collected data that relate to the aim of this study from the teachers at their workstations, at English-medium high schools in South Africa. During the data collection process, whilst participants were giving their experiences and views regarding the phenomenon, the researchers carefully observed the participants' emotions and reactions.

\subsection{Population and Sample}

The population comprises experienced and beginning teachers. It is usually not feasible to work with the whole population hence participants were purposefully selected to offer the best information to address the research aim and question. Purposeful sampling was done to select the research participants. In a purposeful sampling, specific cases or individuals are selected due to their massive knowledge about the topic $[45,46]$. A total target population of this study consisted of teachers in eight English-medium high schools in Welkom, South Africa. In each school, six experienced teachers who served as 
mentors to the Post Graduate Certificate in Education (PGCE) and Baccalaureus Educationis (B Ed) fourth-year student teachers of the Central University of Technology, Free State in the past three years were interviewed. Additionally, three beginning teachers who did not have more than two years' experience in the education system were selected, because of the sufficient information and experience they had on how teacher mentoring occurs in schools. In each school, a minimum of six core subjects was offered to the Further Education and Training (FET) band to meet the promotion requirements of progressing to the next grade. Therefore, the group of six experienced teachers selected was a representation of any of the six core subjects offered at a particular school and three beginning teachers per school were a sizeable number, considering the limited number of new recruits. Table 1 below illustrates a total number of 72 participants who participated in this research.

Table 1. Distribution of participants

\begin{tabular}{|c|c|c|c|c|}
\hline Participants & $\begin{array}{c}\text { Group } \\
\text { members }\end{array}$ & Questionnaires & $\begin{array}{c}\text { High } \\
\text { schools }\end{array}$ & Totals \\
\hline Mentors & 6 & & 8 & 48 \\
\hline $\begin{array}{c}\text { Beginning } \\
\text { teachers }\end{array}$ & & 3 & 8 & 24 \\
\hline
\end{tabular}

Table 1 shows that data were collected from eight high schools. There were two kinds of participants, namely mentors and beginning teachers. Mentors participated in group interviews. For each school, there was one group consisting of six mentors. Three beginning teachers from each school responded to the open-ended questionnaire.

\subsection{Data Collection Instruments}

The researchers used group interviews and an open-ended questionnaire to collect data in this study. The group interviews were used to obtain as much information as possible regarding the research question. An open-ended questionnaire was used to obtain the relevant data from the beginning teachers. Open-ended items in the questionnaire elicited information that sought to discover how beginning teachers had experienced their mentoring processes at their respective schools. The researchers requested each of the selected schools to form a group consisting of six mentors who were to go through a 30-60-minute interview.

\subsection{Ethical Considerations}

Research ethical standards were observed in this study. An approval to the research at the schools was obtained well in advance. The researchers arranged and held preliminary interview meetings with the participants to introduce themselves, establish an appropriate rapport and clarify important aspects of the study, such as the purpose and aim of the research as well as the contents of the instruments to be used. During the preliminary meeting, a consent form was issued which participants signed. The consent form outlined all the relevant information about the study and the procedure that was to be followed during the group interviews, including the recording of the sessions and who was to have access to the recording or read the transcript. Ethical values which all participants, especially the members of groups, were to live up to were thoroughly explained to ensure that all participants knew what was expected of them. This was done to avert unethical behavior during and after the collection of data. Members of the groups were advised that whatever was discussed during the group interviews was not to be divulged and that sexist and racist language was not acceptable. The researchers committed to demonstrating respect and not being judgemental.

\subsection{Data Analysis and Interpretation}

Inductive content analysis was used in this research. Data collected from the participants through group interviews and an open-ended questionnaire were transcribed then anonymised and read several times to find words, phrases, ideas, or opinions that stood out in the data and arranged them into workable units or categories. This was done to develop codes and themes. Various themes and subthemes emerged from the short sentences. Data were narrated in such a way that original meanings or participants' opinions were retained. Participants were quoted verbatim. The findings of the research were used to make conclusions.

\section{Findings and Discussions}

The findings of this study reveal that beginning teachers receive personal and professional help from their fellow experienced colleagues, especially in the aspects such as gaining confidence, building a positive attitude, handling learners, time management and learner assessment. Findings also reveal that mentoring is not mandatory, no time is set aside for it, proper attention and support is not received from the school management team (SMT), it is haphazard, and progress cannot be traced. The findings reveal that experienced teachers do assist beginning teachers in challenges which they usually experience during their first year of employment. Findings also indicate, as put by a teacher in Focus Group 1:

Currently, there is no formal written tool which stipulates how mentoring should unfold, we just approach it through experience, and this usually causes problems as it cannot be enforced and measured.

Findings further indicate that mentoring is an important aspect of teacher development; it should not be left to chance or be the sole responsibility of the heads of department (HoDs) and some teachers as it happens. 
Findings further reveal that mentoring is not taken seriously as it does not receive support from the school management team (SMT) and the district office. A teacher from Focus Group 2 voiced:

I take it that new teachers were mentored enough during practice teaching. They are now no longer babies and should be able to do things on their own without depending on us.

Another teacher from the same focus group counteracted the above notion and emphasised that:

Not everything can be learned during training, being in the field present situations that are sometimes better handled through experience; after all, we also got help when we were newcomers. A good thing here is, we use team working where if we are on the same grade, we work together to show each other what should happen and also tackle problems together. A new person is checked time and again to see if he is on the right track and is moving with us.

A teacher from Focus Group 3 said:

I expect a person who needs help to come to me and not me going after her, but sometimes there are those who are shy and would not consult when they have problems, in this case, formal mentoring would assist.

Mentors understand mentoring as a tool that beginning teachers need to be shown better ways of handling learners, as they seem to have low self-esteem, they cannot handle the assembly or participate in the staff meetings. Mentors have also indicated that sometimes beginning teachers look stressed when they are to present lessons in some other classes where learners are troublesome. A teacher in Focus Group 8 confessed that in an experience, one of the beginning teachers could literally not go to classes because the learners were unruly and openly defied her; they even said this to her face:

You can do what you want to do, we are not going to listen to you because you don't know the subject.

Another teacher in the same focus group interrupted by saying:

Sometimes when you listen to them delivering the content you feel like stopping them and taking over the lesson.

This shows a need for formal mentoring for beginning teachers in this area. The other area of development is time management. Beginning teachers need to learn to use time effectively. According to the participants, beginning teachers forever complain about the workload, but when they have free periods, they rush down to their cell phones instead of doing paperwork, like planning, setting tests and marking.

Assessment is also a challenge which is experienced by beginning teachers. This assertion was corroborated by a teacher in Focus Group 5 who claimed that:
Some of these beginning teachers don't apply Blooms' taxonomy technique of varying questions; they ask low order questions or do the cut and paste.

Another area of concern that should be investigated is the attitude of beginning teachers. This has been mentioned by a teacher in Focus Group 4 who said:

Sometimes the attitude of beginning teachers leaves much to be desired, you would make efforts to show them something, but they would deliberately not implement or follow what you showed.

Findings indicate that beginning teachers are found wanting in terms of proper ways of handling learners, time management, assessment and displaying the correct attitude towards all stakeholders. Findings further indicate that the alluded challenges could be alleviated if an effective and efficient mentoring programme that seeks to address emotional and other teaching aspects could be implemented.

Findings indicate that mentoring is not necessarily spontaneous and therefore not everyone can become an effective mentor. Mentors need to be people of high integrity who display good work ethics and ethos, as one of the beginning teachers said:

They should be respected by colleagues and all stakeholders at all levels.

Mentors need to demonstrate a good attitude towards their work and their seniors, colleagues, and the entire school populace. Findings reveal that mentors are to be tolerant and empathetic. They need to be patient and determined in their effort to grow the beginning teachers professionally. A beginning teacher had this to say:

Mentors should be disciplined and have a love for work and people.

Some beginning teachers have stated that mentors should possess good time management skills. They need to be up to date with their work and make provision to talk or meet with their mentees. Another beginning teacher mentioned:

A mentor should be both a strategic and tactical thinker. Should make positive critics and be able to appreciate good work as by so doing a mentee would open up and be free to ask for help that would relate to improved classroom management and overall learner improvement.

Findings further reveal that effective formal mentoring requires matching of mentors and mentees according to common interests and specialisation of subjects. One beginning teacher stated that:

My mentor was assigned to me by our HoD; we are in the same department, teaching the same subject but in different grades. Honestly speaking we don't have interests in common and as a result, I don't benefit much from her, I wish I were given a chance to choose who to be my mentor. 
Most beginning teachers suggest that mentees should have a say in who should be their mentors and that informal staff meetings where beginning teachers could make connections with experienced staff before the actual allocation of mentors should be done. This would allow the beginning teachers the opportunity to have input as to who they would like to have as their mentors.

The study also reveals that effective mentors are usually the people who possess a strong personality and professional qualities as well as extensive practise skills. Schatz-Oppenheimer [48] states that mentors who have personality-related qualities demonstrate a certain innate set of qualities which make them unique and acceptable to their fellow colleagues. This notion is supported by this study's participants who link qualities of mentoring to caring, integrity, assertiveness, flexibility, tolerance, teamwork, ability to form and maintain interpersonal relationships and the ability to motivate and influence mentees to develop personally and professionally. The above assertions are corroborated in the following comment by an experienced teacher who said:

Although there is a belief that every experienced teacher has the potential to mentor, it depends on the discretion of the HoD who does he see as a better person to mentor. For example, a Maths teacher may be appointed and we are four experienced teachers in that department, HoD will not assign all of us but one particular teacher whom he sees befitting for the duty based on amongst other things conduct, personality and performance.

An understanding created by participants is that not everyone can be a good mentor. Over and above the previously mentioned qualities, mentors need to possess extensive professional sense and knowledge, which would include awareness of ones' professional boundaries and willingness to grow and the ability to identify the beginning teachers' areas of development. In addition, Orland-Barak and Hasin [49] postulate that mentors need to plan and develop sound mentoring programmes and adhere to professional ethos and ethics. Unlike the mentioned personality-related qualities which are said not to be acquired through training, the professional related qualities may be acquired through suitable professional training; therefore, mentors need proper training to function effectively. A teacher in Focus Group 4 explained:

Ideally, every experienced teacher should be capable of mentoring but because the world keeps on changing and whatever knowledge one has might not be enough or relevant it is, therefore, necessary that we should also update ourselves and be workshopped on new trends.

Practice-based skill is mentioned as the other skill or quality necessary for effective mentoring and it is a three-dimensional activity - namely emotional, social, and cognitive [48]. Feiman-Nemser [50] outlines that the cognitive part entails the ability to analyse and interpret content according to required theoretical packages. The emotional part is associated with recognition, acceptance and understanding of beginning teachers as a unique individual with unique challenges. Lastly, the social part has to do with unleashing beginning teachers' potential to socialise and to work with others as part of the team in a healthy and safe corporate environment.

The findings confirm that mentors need to be properly prepared and mentoring programmes be properly structured. There should be a well-designed document which outlines what formal mentoring is about, what it aims to achieve and how it is to be carried out at the school. Most beginning teachers have indicated that those earmarked as mentors should be carefully selected based on the track record of proven success, knowledge, and skills. Participants further elaborated that a mentor should be in the system for more than three years, be good in their subjects and be willing to assist or share knowledge and skills. The mentor's personal and professional experiences and capacities form the basis for qualities required for mentoring work. Mentoring embodies emotional, social, and cognitive aspects. Some of these aspects may be newly acquired while others may just be developed.

Findings further indicate that since mentors are also teachers and have their duties it would be fair and encouraging to reward them for extra efforts at mentoring. Moreover, rewards cannot necessarily be in monetary terms but also in the form of appreciation certificates, reduced duties and better working conditions. Furthermore, beginning teachers and their mentors could thrive and flourish when all complexities, challenges, and motivating factors such as monetary and non-monetary rewards could be taken into consideration. A teacher in Focus Group 6 emphatically stated:

Remuneration package should be improved and be made attractive to keep teachers in the system, young teachers are enticed by private sectors and they leave. The other teacher interjected, we are also frustrated, if it were possible, we would all quit. There is too much administration work, paperwork.

Another teacher, also in the same focus group, stated: It would be better if we were at least bought computer programmes that we could use to set tests, marking and for some other things to reduce the burden.

The notions above are backed by Cropanzano and Wright [51], who argue that in general, happy people perform better and are willing to help others than the less happy or unhappy people in a social interaction setting. Similarly, happiness is a feeling of pleasure usually extrapolated from pleasant environmental events and tends to respond positively to therapeutic interventions.

Findings further reveal that at any workplace, including 
schools, there are those people who are identified as unhappy. They are sensitive to threats, do not want to take risks and are defensive and cautious around their fellow colleagues. They are also characterised as less optimistic and complaining a lot. The following beginning teachers' responses corroborate the above assertions:

Not all mentors are willing to assist, they complain that they already have too much work to do and can't afford any additional responsibility.

A beginning teacher's response reflecting mentors' willingness to assist regarding mentoring:

Most mentors are prepared to exchange information, share their skill, knowledge, and expertise with inexperienced teachers.

The above response shows some mentors have a positive attitude towards mentoring. A teacher in Focus Group 6 stated:

We are willing to guide and help them but sometimes they seem not keen to learn and don't implement the things we suggest to them:

A teacher in Focus Group 4 'nailed it' when stating: I am always happy to assist where I can because I like seeing new a teacher succeeds and doing his share of making a positive difference in the lives of learners. If a teacher struggles other teachers get affected and so are learners.

Findings reveal that there are also happy teachers who show a positive attitude towards their work and are willing to take risks and use opportunities available to increase their valuable resource. Likewise, teachers who look happy are more open, outgoing, confident, optimistic, and helpful to their colleagues.

Despite the highlighted possibility of teachers' displaying different attitudes based on their levels of happiness, the findings reflected that in general, most of the experienced teachers are more willing to assist their fellow beginning colleagues. However, it would be more convenient and better if the timetables of mentors and mentees could be such that the parties are free at the same time to afford them an opportunity to meet.

The given perspective of happy and unhappy people presents a possibility that teachers may display different attitudes towards their work and one another based on their levels of happiness. This is confirmed by the findings of this study, which have revealed that even though there are those mentors who seem unhappy and unwilling to assist beginning teachers unless there is some sort of compensation for extra efforts, most of the mentors are motivated to work hard and willing to assist their fellow beginning teachers without expecting any kind of reward.

\section{Conclusions and Recommendations}

The literature and responses from both mentors and beginning teachers indicate mentoring as a process in which the experienced and the inexperienced teacher engage in a relationship that seeks to guide and help the latter with work-related matters. Findings also indicate that effective mentors are best performers who are knowledgeable, experienced, and committed. In South African schools, there is no official formal mentoring program; HoDs and experienced teachers do find means and ways to help the beginning teachers to navigate through new roles of teaching. It is revealed that the attitudes and behavior of both mentors and mentees affect mentoring relationships and that happy mentors are more willing to help as compared to those 'grumpy' ones who forever complain. Furthermore, lack of time as well as inadequate material and financial resources, hamper mentoring processes. Teachers have a lot of work to do. They hardly find time to meet for other work-related things or even to socialise as colleagues, because they have an excessive workload. Since there is no mentoring blueprint, experienced teachers are not sure how to go about it. At times they are not able to render the expected support due to lack of knowledge on other aspects and lack of resources. There is, in some instances, a lack of trust between beginning teachers and experienced. All these findings reveal that the mentoring process of beginning teachers is ineffective at schools in South Africa. However, it is easy to talk and learn when mentors and mentees are open, honest and have positive attitudes. Socialisation into teaching should be regarded as an interactive process of interpretation between the beginning teacher and the school as a collective. Mentoring should be made part of the school development plan. Experienced teachers are to receive training in mentoring. There should be some means or ways of identifying compatible mentoring partners. Beginning teachers should receive training on professional ethics and ethos. This process will improve relationships between mentors and their beginning teachers. Therefore, this study recommends that the following mentoring model should be implemented at schools. This model aims to socialise and to render personal and professional support to beginning teachers. It is an original model that has its own distinctive features and dynamics. It is to be implemented continually for a period of two years with its first four objectives being addressed during the first year and the last two objectives during the second year. The model will be implemented during school hours according to a specific schedule. The objectives of the model as informed by the study are to 1) ensure compatibility matching of mentors to mentees, 2) provide training for mentors, 3) determine the needs of beginning teachers, 4) ensure the smooth transition of beginning teachers into their career, 5) provide effective professional guidance and support for beginning teachers, and 6) foster accountability. 


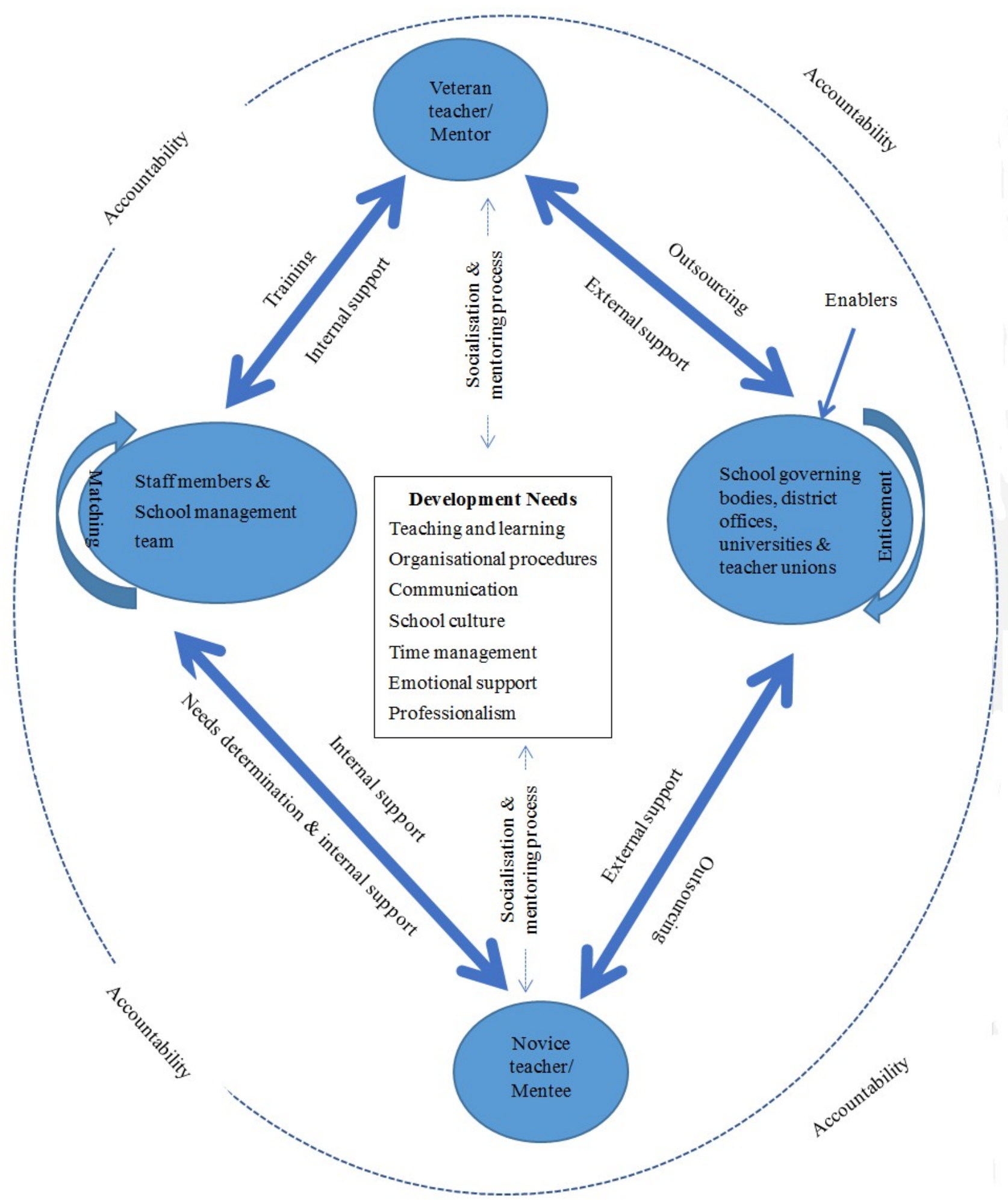

Figure 2. A model for effective formal mentoring of beginning teachers

Figure 2 displays a model for effective formal mentoring of beginning teachers that gives a planned transformative approach to implementing the six interrelated components of a formal mentoring process. During the implementation of the mentoring process, all members across all levels of the organisation cooperate and communicate with one another so that a culture of responding to the needs of beginning teachers and all other staff members is cultivated. The six components of the model can be implemented as follows: 


\section{The six major interrelated components of the model}

To achieve the objectives of the model for effective formal mentoring of beginning teachers, six interrelated components are used, namely: staff members and the school management team (SMT), experienced teachers/mentors, beginning teachers /mentees, development needs and enablers such as the school governing body (SGB), union representatives, district offices and universities, as well as accountability. The operational framework or roles of each component are provided in the following section.

\section{Staff members and the school management team}

A systematic matching process is necessary to ensure compatibility between experienced and beginning teachers, which is objective number one. The rise or fall of the mentoring process depends on the quality of the professional and personal match between experienced and beginning teachers. SMT, together with all teaching staff, meets and discusses the matching of mentors to mentees. Beginning teachers are also staff members and have every right to make inputs on whom should be their mentors. Key points to be considered when matching are experience, expertise, performance, leadership, and personality. Mentors are people who have been in the system for at least five years. They should be offering the same subject or grade as the mentee, have a thorough content knowledge or have an acceptable track record or performance in the area in which they will be assisting. The mentor's personality should be compatible with that of the mentee.

\section{Mentors}

To achieve objectives two and three, mentors must know exactly what is expected of them so they can live up to the standards of the mentoring programme. Prior to the commencement of the mentoring programme and based on the specified needs of the beginning teachers, the mentor might require training. Along with this preparation, SMT and all other parties are expected to cooperate and show continuous support of the mentoring process. A mentor will use this mentoring model to develop a specific mentoring programme designed to address the specific needs of the mentee as determined by both parties. The programme will then reflect the specific development needs of the mentee in which the mentor is to provide guidance and support.

\section{Development needs}

To achieve objective number four, the uniqueness of the beginning teachers and their specific needs will be considered. Beginning teachers need emotional support based on trust, acceptance, and empathy in order to build their self-esteem and sense of achievement. Social support somehow helps them to adapt to the tradition and culture of the school quickly and smoothly and it also encourages a collaborative learning environment, while professional support focuses on teaching and learning aspects. Beginning teachers' mentoring needs are in teaching and learning, organisational procedures, communication, school culture, time management, emotional support, and professionalism [52]. It may not be possible for the mentor to assist with some other needs and in that case, assistance from colleagues, the SGB, district officials that are Department of Basic Education (DBE) officials, experts from universities and teacher union officials may be required. Outsourcing of stakeholders might require some enticement when the SGB's assistance is much needed.

\section{Mentees}

As with mentors, mentees should possess excellent interpersonal communication skills - that is being able to communicate their needs politely and eloquently. This ability can help boost the morale of the parties and eliminate any effects of discouragement and disillusionment that might prevail during the mentoring process. Mentees should be engaged in a preparatory workshop dealing with the development of interpersonal skills, to strengthen their abilities to participate in the personal and professional exchange process with their mentors. They need to understand their predicament and appreciate an endeavour on the part of mentors and the school to help and support them. The mentoring process happens because mentees already experience challenges which need to be addressed. It is therefore expected of them as adults and mature people to show responsibility and positive attitudes towards their learning. As indicated in the andragogy theory of Knowles, adults are aware of their needs and what is in it for them even before they decide to go through the mentoring process [53]. Their commitment to the programme should be motivated by the envisaged internal and external benefits, such as increased self-esteem, improved human relations, job satisfaction, and increased productivity and job promotions.

\section{Support team}

The support team in the mentoring process should include the SGB, teacher unions, district officials and experts from universities. The support team are enablers and can provide many benefits to the mentoring process. The SGB is entrusted with the governance of the school. Some of its duties are to:

- Promote the best interests of the school and strive to ensure its development through the provision of quality education for all learners at the school.

- Support the principal, educators, and other staff of the school in the performance of their professional functions.) [54, pp. 8-9].

Furthermore,

A governing body may establish committees, including 
an executive committee; and appoint persons who are not members of the governing body to such committees on grounds of expertise, but a member of the governing body must chair each committee [54, p. 12].

The above functions indicate that it is the responsibility of the SGB to ensure the smooth running of the school and its overall improvement. The SGB and SMT's involvement in the mentoring programme is well within their jurisdiction. Their active participation will highlight the importance of the mentoring programme and challenge all other members to take it seriously. It will also eliminate the unnecessary hassles that might erupt during the implementation of the mentoring process, especially when money or some material resources are needed.

Mentoring is a matter of human resource. It is usually advisable to work with the unions when human resources are involved. Unions can guide and advise accordingly on labor issues. They may also be able to resolve personality conflicts that may occur between a mentee and mentor. District offices and universities can bridge the gap where mentees and mentors cannot reach each other. Involvement of universities and district offices can ease the mentor teachers' burden of trying to address beginning teachers' wide range of personal and professional needs. Instead of wasting a lot of time to figure out how to address a particular need, a mentor teacher can save time by outsourcing an expert from the university or district office. In this way, mentors can focus on things within their reach or area and level of specialty.

\section{Accountability}

This model is a deliberate and organised plan of accountability. The mentoring programme is purely developmental and is in no way trying to regulate and frustrate the parties with evaluation processes, portfolios, or any paperwork. However, the mentor will be expected to report the progress of the mentee and the mentee will also be expected to reflect on the mentoring programme and its benefits. The model suggests that the mentee and mentor should meet throughout the year as per the agreed dates reflected on the plan. Meetings will take place during defined periods that are factored into the timetable within school hours. This is done to make the mentoring programme as effective, sustainable, swift, and enjoyable as possible.

\section{REFERENCES}

[1] Stansbury, K., \& Zimmerman, J. Lifelines to the Classroom: Designing Support for Teachers. https://files.eric.ed.gov/fulltext/ED447104.pdf. (accessed May. 24, 2021).
[2] Ingersoll, R, Merril, L., Stuckey, D. \& Collins, G. Seven Trends: The Transformation of the Teaching Force. https://repository.upenn.edu/cpre_researchreports/108/. (accessed May. 24, 2021).

[3] He, Y. Strength - Based Mentoring in Pre - Service Teacher Education: A Literature Review. Mentoring \& Tutoring: Partnership in Learning, vol.17, no. 3, pp.263-275. 2009, DOI: 10.1080/13611260903050205.

[4] Ingersoll, R., \& Strong, M. The Impact of Induction and Mentoring Programmes for Beginning Teachers: A Critical Review of the Research. Review of Education Research, vol. 81, no.2, pp.201-233, 2011, https://doi.org/10.3102/00 34654311403323.

[5] European Commission. Developing Coherent and System-Wide Induction Programmes for Beginning Teachers: A Handbook for Policy Makers. https://ec.europa.eu/assets/eac/education/policy/school/doc /handbook0410_en.pdf. (accessed May. 15, 2021).

[6] Management Mentors. managementmentors.com. http://www.management-mentors.com/about/corporate-me ntoring-matters-blog/bid/90851/What-is-the-difference-bet ween-INFORMAL-and-FORMAL-MENTORING. (accessed Jul. 22, 2016).

[7] Kahle-Piasecki, L. Making a Mentoring Relationship Work: What is Required for Organizational Success. Journal of Applied Organisation and Economics, vol. 12, no. 1, pp. 46-56, 2011,http://www.digitalcommons.www.n a-businesspress.com/JABE/PiaseckiWeb.pdf.

[8] Fragoulis, I. Recording of Primary Education Teachers' Opinions on the Use of Mentoring in the Frame of Implementation of Innovative Educational Programmes. International Education Studies, vol.7, no. 3, pp.51-59. 2014, URL: http://dx.doi.org/10.5539/ies.v7n3p51.

[9] McLaughlin, C. Mentoring: What Is It? How Do We Do It and How Do We Get More Of It? HSR: Health Services Research, vol. 45, no. 3, pp. 871-884, 2010. doi: 10.1111/j.1475-6773.2010.01090.x.

[10] Holmes, D. H. Mentoring: Making the Transition from Mentee to Mentor. Circulation AHA Journals, vol. 121, no.2, pp. 336-340, 2010, DOI: 10.1161/CIRCULATIONA HA.108.798321.

[11] Inzer, L., \& Crawford, C. B. A Review of Formal and Informal Mentoring: Processes, Problems, and Design. Journal of Leadership Education, vol. 4, no.1, pp.31-50, 2005. DOI:10.12806/V4/I1/TF2.

[12] Olson, D., \& Jackson, D. Expanding Leadership Diversity Through Formal Mentoring Programmes. Journal of Leadership Studies, vol. 3, no. 1, pp.47-60, 2009, DOI:10.1002/jls.20095.

[13] Palsa, M., \& Rosser, M. H. Mentoring and Diversity: A Review of the Literature. https://files.eric.ed.gov/fulltext/E D504861.pdf. (accessed May. 24, 2021.

[14] Hoffer, S. A Formal Mentoring Programme and its Relationship to Academic Success and Retention Rates of First Time Freshman College Students at Walla Walla University. https://digitalcommons.andrews.edu/dissertatio ns/443 (accessed Jul. 20, 2018).

[15] Vikaraman, S. S., Mansor, A.N. \& Hamzar, M.I.M. 
Mentoring and Coaching Practices for Beginner Teachers-A Need for Mentor Coaching Skills Training and Principal's Support. Creative Education, vol. 8, no. 1. pp. 156-169, 2017, DOI: 10.4236/ce.2017.81013.

[16] Moss, J. A Partnership in Induction and Mentoring: Noticing How we Improve Our Practice. Australian Journal of Teacher Education, vol.35, no.7, pp.43-53, 2010, http://dx.doi.org/10.14221/ajte.2010v35n7.4.

[17] Dziczkowski, J. Mentoring and Leadership Development. The Educational Forum, vol.77, no.3, pp.351-360, 2013, DOI: $10.1080 / 00131725.2013 .792896$.

[18] Tummons, J., Kitchel T. \& Garton, B.L. Expectation Congruency and Psychosocial Support in Formal Agriculture Teacher Mentoring Relationships. Journal of Agricultural Education, vol.57, no.4, pp.68-85, 2016, https://doi.org/10.5032/jae.2016.04068.

[19] Beane-Katner, L. Anchoring a Mentoring Network in a New Faculty Development Programme. Mentoring \& Tutoring: Partnership in Learning, vol.22, no.2, pp.91-103, 2014, https://doi.org/10.1080/13611267.2014.902558.

[20] Ehrich, L. H, Hansford, B. \& Enrich, J.F. Mentoring Across the Professions: Some Issues and Challenges. Practical Experiences in Professional Education. A Transdisciplinary Approach, pp.93-113, 2011, https://ro.uow.edu.au/edupapers/1070.

[21] Hobson, A. A., Ashby, P., Malderez, A., \& Tomlinson, P.D. Mentoring Beginning Teachers: What we Know and What we Don't. Teaching and Teacher Education, vol.25, no.1, pp.207-216, 2009, DOI: 10.1016/j.tate.2008.09.001.

[22] Newfoundland and Labrador Teachers' Association. Mentoring Beginning Teachers, http://files.nlta.nl.ca/wp-c ontent/uploads/public/documents/tchrmntr_hdbk.pdf.(acce ssed May. 15, 2021).

[23] Blinn-Pike, L. "The Benefits Associated with Youth Mentoring Relationships," In the Blackwell Handbook of Mentoring: A multiple perspectives Approach, 2007, pp.163-187.

[24] Rodrigues, J. A. Not Intuitively Obvious: Transition to the Professional Work Environment. Xlibris US, 2009.

[25] Nghaamwa, T. An Analysis of the Influence of Induction Programmes on Beginner Teachers' Professional Development in the Erongo Region of Namibia, file://C:/Users/user/Downloads/nghaamwa analysis 2017 .pdf, (accessed Mar. 5, 2020).

[26] Dishena, R. \& Mokoena, S. Novice Teachers' Experiences of Induction in Selected Primary Schools in Namibia, Eurasian Journal of Educational Research, no.6, pp. 335-354, 2016, http://dx.doi.org/10.14689/ejer.2016.66.19.

[27] Wechsler, M. E., Caspary, K., Humphrey, D.C. \& Matsko, K. K. Examining the Effects of New Teacher Induction, https://www.siue.edu/ierc/pdf/SRI-Examining-Effects-of-I nduction-April-2010.pdf.

[28] Kutsyuruba, B. G., Godden, L., Covell, L., Matheson, I. \& Walker, K. Understanding the Contextual Factors Within Teacher Induction and Mentoring Programmes an International Systematic Review of Research. https://educ.queensu.ca/sites/webpublish.queensu.ca.educ
www/files/files/People/Faculty/Systematic\%20Review\%2 0Teacher\%20Induction\%20and\%20Mentoring.pdf. (accessed Jan. 18, 2020).

[29] Ambrosetti, A. Are You Ready to be a Mentor? Preparing Teachers for Mentoring Pre-service Teachers. Australian Journal of Teacher Education, vol.39, no.6, pp.30-42, 2014, DOI: 10.14221/ajte.2014v39n6.2.

[30] Ingersoll, R. Beginning Teacher Induction: What the Data Tell Us. Phi Delta Kappan, vol.93, no.8, pp.47-51, 2012. DOI: $10.2307 / 23210373$.

[31] Buchanan, J., Prescott, A., Schuck, S., Aubusson, P. \& Burke, P. Teacher Retention and Attrition: Views of Early Career Teachers. Australian Journal of Teacher Education, vol.38, no.3, pp.112-129, 2013, DOI: 10.14221/ajte.2013v 38n3.9.

[32] Isenberg, E., Glazerman, S. I., Bleeker, M., Johnson, A., Lugo-Gil, J. Grider, M., Dolfin, S. Britton, E. \& Ali, M. Impacts of Comprehensive Teacher Induction: Results from a Randomized Controlled Study.https://files.eric.ed.g ov/fulltext/ED511788.pdf (accessed Oct. 6, 2018).

[33] Straus, S.E., Johnson, M.O., Marquez, C. \& Feldman, M.D. Characteristics of Successful and Failed Mentoring Relationships: A Qualitative Study Across Two Academic Health Centers. Acad Med, vol.88, no.1, pp.82-89, 2013, DOI: 10.1097/ACM.0b013e31827647a0.

[34] Cho, C.S., Ramanan, R.A. \& Feldman, M.D. Defining the Ideal Qualities of Mentorship: A Qualitative Analysis of the Characteristics of Outstanding Mentors. American Journal of Medicine, vol.124, no.5, pp.453-458, 2011, DOI: 10.1016/j.amjmed.2010.12.007.

[35] Smith, C.Y.I. The Role of Mentoring in the Professional Development of Educators at Secondary Schools. https://repository.up.ac.za/bitstream/handle/2263/52972/S mith_Role 2015.pdf?sequence $=1 \&$ isAllowed=y. (accessed Mar. 5, 2020).

[36] Salleh, H., \& Tan, C. Beginning Teachers Learning from Others: Mentoring in Shanghai Schools. Australian Journal of Teacher Education, vol.38, no.3, pp.151-165, 2013, DOI:10.14221/ajte.2013v38n3.1.

[37] Iancu-Haddad, D., \& Oplatka, I. Mentoring Beginning Teachers: Motives, Process, and Outcomes from the Mentor's Point of View. The New Educator, vol.5, no.1, pp.45-65, 2009, DOI: 10.1080/1547688X.2009.10399563.

[38] Corrigan, D., \& Loughran, J. Mentoring for the Teaching Profession: Snapshots of Practice. British Educational Research Association Annual Conference, Heriot-Watt University, Edinburgh, 3-6 Sep 2008, pp. 1-13, http://www.leeds.ac.uk/educol/documents/174579.pdf.

[39] McCollum, I.P. "Beginning Teachers' Perceptions of a Teacher Mentoring Program" (2014). Walden Dissertations and Doctoral Studies.https://scholarworks.wa ldenu.edu/dissertations/152 (accessed Oct. 04, 2017).

[40] Aspfors, J. Induction Practices: Experiences of Newly Qualified Teachers. https://www.researchgate.net/publicati on/261214377_Induction_Practices_Experiences_of_Newl y_Qualified_Teachers. (accessed Oct. 04, 2017).

[41] Smit, T., \& Du Toit, P. H. Transforming Beginner Teacher 
Mentoring Interventions for Social Reform. South African Journal of Education, vol.36, no.3, pp.1-12, 2016, doi: 10.15700/saje. v36n3a1134.

[42] Nantanga, S. Beginning Teachers' Experiences of Induction in Selected Schools in Oshana Region, Namibia. http://uir.unisa.ac.za/bitstream/handle/10500/14200/dissert ation_nantanga_sp.pdf?sequence $=1 \&$ isAllowed $=y$, (accessed Oct. 04, 2017).

[43] Morrison, C. Slipping Through the Cracks: One Early Career Teacher's Experiences of Rural Teaching and the Subsequent Impact on her Personal and Professional Identities. Australian Journal of Teacher Education, vol.38, no.6, pp.116-135, 2013, DOI:10.14221/ajte.2013v38n6.1.

[44] Deacon, R. The Initial Professional Development of Teachers: A Literature Review.https://www.jet.org.za/reso urces/deacon-initial-professional-development-of-teachersliterature-review-feb15web.pdf. (accessed Oct. 04, 2017).

[45] McMillan, J. H. Educational Research. Fundamentals for the Consumer (6th ed.). Pearson, 2012, pp.1-415.

[46] Leedy, P. D., \& Ormrod, J. E. Practical Research: Planning and Design (10th ed.), Pearson, 2013, pp.1-363.

[47] Creswell, J. W. \& Poth, C.N. Qualitative Inquiry and Research Design: Choosing among Five Approaches. (4th ed.), SAGE, 2018, pp. 1 - 459 .

[48] Schatz-Oppenheimer, O. Being a mentor: novice teachers' mentors' conceptions of mentoring prior to training. vol.43, no.2, pp.274-292, 2017, https://doi.org/10.1080/19415257. 2016.1152591 .

[49] Orland-Barak, L., \& Hasin, R. Exemplary Mentors' Perspectives Toward Mentoring Across Mentoring Contexts: Lessons from Collective Case Studies. Teaching and Teacher Education, vol.26, no.1, pp.427-437, 2010, https://doi.org/10.1016/j.tate.2009.05.009.

[50] Feiman-Nemser, S. Helping Novices Learn to Teach Journal of Teacher Education, vol.52, no.1, pp.17-30, 2001, DOI: $10.1177 / 0022487101052001003$.

[51] Cropanzano, R., \& Wright, T.A. When a "Happy" Worker Is Really a "Productive" Worker: A Review and Further Refinement of the Happy-Productive Worker Thesis. Consulting Psychology Journal Practice and Research, vol.53, no.3, pp.182-199, 2001, https://doi.org/10.1037/10 61-4087.53.3.182.

[52] Bridge. A BRIDGE Resource: Mentorship in Teacher Development.https://www.bridge.org.za/wp-content/uploa ds/2016/11/Mentorship-in-Teacher-Development-Resource -Pack-20161109.pdf. (accessed July. 14, 2021).

[53] Knowles, M. The Adult Learner: A Neglected Species. Houston: Gulf Publishing Company. (1973).

[54] Republic of South Africa (RSA). The South African Schools Act (Act 84 of 1996). https://www.gov.za/sites/def ault/files/gcis_document/201409/act84of1996.pdf.(accesse d July. 14, 202 1 ). 